\title{
GLOCALIZATION - AN OBJECTIVE CONDITION FOR A SUCCESSFUL MANAGEMENT OF THE MULTINATIONAL COMPANIES IN THE CONTEXT OF THE ECONOMIC GLOBALIZATION
}

\author{
Leontin STANCIU \\ "Nicolae Bălcescu" Land Forces Academy, Sibiu, Romania \\ leontinstanciu@yahoo.com \\ Cristian-Lucian STANCIU \\ S.C. Marquardt Shaltsysteme S.C.S., Sibiu, Romania \\ stanciu_cristian_ro@yahoo.com
}

\begin{abstract}
Currently, one of the most concise expressions of the phenomenon of economic globalization is the extent of the organization of production on a global or regional basis and the integration on new criteria, of a functional nature, of the activities within it. A decisive role in the organization of production processes abroad is played by multinational companies, which, in order to achieve their objectives, most "export" not only know-how, but also management methods and techniques, applicable in the countries of origin. In this article, the authors aim to identify and highlight the main arguments that support the glocalization as an objective necessity and, at the same time, a viable solution to achieving a successful management of the multinational companies, to ensure a win-win relationship between them and the communities and the local markets in which they operate, in the context of economic globalization.
\end{abstract}

KEYWORDS: globalization, economic globalization, economic glocalization multinational companies, management

\section{Introduction}

In a globalized, dynamic and versatile economic environment, changing the market conditions has become a constant feature, forcing the multinational companies to conduct a creative, adaptive and efficient management, making them to constantly use the scientific tools of modern management, to draw attention not only to their own needs and expectations, but also to seek to meet, to a greater extent, the requirements related to the specifics of the local market in which they operate.
In the context of the economic globalization, thinking globally and acting locally is an objective necessity, a prerequisite for exercising an efficient management at the level of the multinational companies and their subsidiaries. From the very beginning, we argue that it is not appropriate to fully adopt, in their original form, different management models, because they can be successful in some markets while they can generate failure in others. For a modern and efficient management, we consider that in 
the conduct of management, an increased attention must be paid to the socio-cultural aspects specific to the local markets in which these companies operate. In a competitive environment, these specific aspects can make a real difference between a multinational company that proves an increased adaptability to the external environment and a multinational company that does not take these aspects into account and applies a common management policy on all the markets in which it operates. Therefore, we argue that glocalization is the solution of a win-win relationship between the multinational companies and the local communities in which the subsidiaries of these companies operate by exercising a management adapted to the cultural specifics of the local markets.

\section{Economic Globalization and} Business Internationalization

Globalization is an intensely debated and analyzed phenomenon in the literature, whose effects, either positive or negative, we continue to feel after such a long time, especially in the current economic, social and epidemic context.

From a conceptual point of view, there is no unity of opinion on its definition, since globalization is an abstract concept, which cannot be highlighted by its physical, easily identifiable dimensions, not being an indicator or a statistical index, determined by more or less complicated computations. There are many who argue that globalization is about increasing the importance of the world market in the international trade and the financial relations. Other analysts argue that globalization is a particularly complex concept, which is based on radical changes in the economic, the socio-cultural and the political life and can no longer be explained by using the classical categorizing apparatus which has meanwhile become fragile and inadequate to the new international phenomena and processes.
(Postelnicu \& Postelnicu, 2000). Then how can we best define this concept?

Globalization, as a dominant phenomenon in the world economy in the recent decades, can be defined as "a continuous decline in the economic importance of the national political borders and a sharp intensification of the economic relations, up to a point where the gap between the domestic and the foreign transactions becomes insignificant or disappears" (Angelescu et al., 2000, p. 398). Most specialists claim that globalization is an eminently economic phenomenon, which involves an increase in the economic interaction of the states, an enhancement of the international trade activities, an augmentation of the capital flows and investments. These economic interdependencies, through their dynamics of the recent years, have transformed the concept of globalization into a leitmotif for the specialists concerned with the topic, but also for the public opinion (Negrea, 2012). The economic dimension of the globalization is its most visible and discussed form, due to specific problems, such as: - increased volume of the international trade and of the direct investment; $\bullet$ globalization of the financial markets • global competition • integrated production; - the existence of the multinational companies, etc.

For a long time, the economic globalization has been a phenomenon generated by unmistakable realities, which has manifested itself in particularly complex forms, sometimes difficult to decipher, and its intensification in the last decades of the twentieth century has created new problems. Thus, in recent years, the major changes in the world economy have generated consistent debates especially among specialists related, in particular, to the following: - the alarming rise of unemployment; - the increased, sometimes difficult to manage inflation - the development of the international 
trade; - the contradictory evolution of the economic integration process - the intensification of the competition - the technological changes; - the environmental degradation, etc. (Constantinescu-Băeșu, 1998).

The economic globalization is the result of considerable efforts of the international cooperation in order to achieve technological progress. Due to this fact, the interdependence between economies and cultures has escalated, and the cross-border trade in goods and services and the labor, investment and information flows have increased at an accelerated rate.

Under the conditions of the contemporary economy, the active participation in the international division of labor constitutes an objective necessity, a primary strategic aim of the development of each country. In this context, foreign trade, as a distinct branch of the national economy, becomes a stimulator of the economic growth, of the business internationalization and, finally, of the economic globalization. The international development of the economic affairs, regardless of the size of the entities or their field of activity, tends to become a condition of the organizational existence, and the business strategy must be adapted to the demands of the globalization (Popa-Paliu, 2009).
The development of the commercial activities outside the national borders, respectively of the internationalization of the economic transactions, is not a novelty in the contemporary world economy, but a main feature thereof. However, after the Second World War, it developed considerably, mainly due to factors such as: - the post-war reconstruction process, - the institutionalization of the international economic relations; $\bullet$ the gradual reduction of the restrictions specific to the international trade and the financial flows; - the reduction of the transport and communication costs; $\bullet$ the diversification of the transport methods; $\bullet$ the expansion of the activity of the multinational and transnational companies, and so on.

The economic globalization is also stimulated by the expansion of the economic relations and the development of an international business environment. By overcoming local, national and regional boundaries, as well as by globally approaching the economic environment, the companies join the general trend of internationalization, being its indispensable vectors. The process of business internationalization, in turn, involves several stages, according to the table below.

Table no. 1

Stages of the business internationalization

\begin{tabular}{|l|l|}
\hline \multicolumn{1}{|c|}{ Stage } & \multicolumn{1}{|c|}{ Specific activities } \\
\hline $\begin{array}{l}\text { Stage I Internationalization of trade in } \\
\text { goods }\end{array}$ & $\begin{array}{l}\bullet \text { international trade operations; } \\
\bullet \text { establishment of commercial offices. }\end{array}$ \\
\hline Stage II - Internationalization of production & $\begin{array}{l}\bullet \text { technology transfers (licensing, franchising, know-how } \\
\text { sales, etc.); } \\
\text { partial or total relocation of some production facilities and the } \\
\text { integration of the goods in the own system of internal and } \\
\text { international distribution; } \\
\text { establishment of production and trade units abroad in the joint } \\
\text { venture system. }\end{array}$ \\
\hline Stage III - Internationalization of the \\
company & $\begin{array}{l}\text { - direct investments, from the creation abroad of assembling and } \\
\text { processing subsidiaries to the complete, industrial and } \\
\text { commercial implantation. }\end{array}$ \\
\hline
\end{tabular}


After analyzing the evolution of the world economy in the recent decades, we can identify a number of characteristics that have profoundly changed its configuration, determined by the economic globalization, such as:

- increasing the tendency to organize production, especially industrial production, on a global scale;

- transferring large sums of money, from one point to another in the world, in real time, due to the advanced information technologies;

- changing the way of thinking and acting of all human communities in favor of opening borders, especially for new technologies;

- multiplying the points of convergence between the states of the world;

- amplifying the role of the multinational companies as "architects of the new global order", etc.

In turn, the economic globalization is the result of considerable efforts of the international cooperation to achieve technological progress, thus developing the interdependency in the national economies and cultures, which has led to a sharp increase in cross-border trade in goods and services, as well as an amplification and diversification of labor, investment and information flows. Also, the economic globalization has continuously broadened the interest in the international, intercultural and comparative dimension of management.

Most research shows that, in essence, the economic globalization is based on three pillars, namely:

- the liberalization of the international financial circuit;

- the labor mobility;

- the existence of the multinational companies and the strategic alliances (Pricop \& Tanţău, 2001).
3. The Multinational Companies a Fundamental Pillar of the Economic Globalization

In an editorial entitled "The World's View of Multinationals", published on January 29, 2000, the British magazine The Economist concluded that the multinational companies are one of the most representative factors of the contemporary economic progress, being also the most visible side of the economic globalization.

For a better understanding of this phenomenon, which deeply marks the contemporary world economy, it is necessary to briefly detail a few aspects, such as:

-defining the multinational companies and their organizational structures;

-the place of the multinational companies in the national and world economies;

-the role that the multinational companies play in the global redistribution of factors of production and in the intensification of globalization.

In recent decades, more and more specialists have been concerned with the issue of the multinational companies, and they have tried to capture, through a comprehensive definition, their economic nature. Thus, Vermen R. (1966) argued that a multinational company is a large firm that includes in its organizational structure industrial branches in at least six countries. Subsequently, with the emergence of medium-sized companies with international activity, this figure was reduced to two countries and, finally, to one. Currently, most specialists accept that a multinational company is a company that has expanded its production and marketing beyond the country's borders and also:

- started operating as a large enterprise at national level, which previously involved a concentration and centralization of capital; 
- diversified its production before starting to internationalize;

- given their national origin, the strength and the weaknesses of the economy will be reflected, to a large extent, in the competitiveness and strategies (management, marketing, etc.) to be adopted.

Currently, the multinational companies have become global economic and financial operators, which internationalize their production and services (Gilpin, 2004). For example, if in 1970, in the first 15 developed countries of the world, there were about 7500 multinational companies, in 1994, in the same states, there were about 25,000 multinational companies. Currently, international statistics show that in the world economy there are over 50,000 multinational companies, with over 280,000 subsidiaries, spread over all the meridians of the globe. They control over $40 \%$ of total private sector assets, existing worldwide, and account for over $35 \%$ of economic goods produced in the entire world economy. Also, according to the statistics of the International Labor Office, these companies concentrate more than $5 \%$ of the active workforce in the world's developing regions and more than $15 \%$ of that of the developing countries.

In Romania, the multinational companies play an important part in ensuring the stability and the development of the business environment. For example, the consolidated turnover of the first 100 multinational companies, active in the Romanian economy in the last decade, has doubled and represents about $30 \%$ of the consolidated revenues at the level of the entire business environment. During the same period, the number of employees increased by over $50 \%$ representing approximately $6 \%$ of the total employees in the local business environment.

The emergence and the development of the multinational companies have profoundly influenced the national and global competitive environment. They must also face competition from the "global industry". At present, the competitive advantages of the companies depend directly on the specifics of the country in which they operate. According to theories related to the economic nature of the multinational corporations, a global industry is one in which the competitive position of the companies in a given country is significantly influenced by their position in other countries and vice versa (Postelnicu \& Postelnicu, 2000). For this reason, the global industry is not a sum of domestic industries, but a sum of connections, in which each participant must fight against the others, on a broad international basis. This distinction is of particular importance in the process of developing the companies' international strategies. Given the existence of a global industry, where the companies need to integrate their activities into the multitude of links between states, it is necessary not only to have an external transfer of assets, but also a transfer of skills. Basically, a global strategy involves, on the one hand, an amplification of the links between the geographically separate activities of subsidiaries and parent companies, and, on the other hand, an optimization of the local advantages of each subsidiary by satisfying the demand on the target market, according to the principle that "the company must think globally, but act locally".

The natural consequence of this approach is the tendency of the specialization of the subsidiaries by types of activities that capitalize on the comparative advantage of the host country. Thus, the labor-intensive manufactures are located in the geographical areas with cheap labor, the research and development centers of the multinational companies operate near universities in countries with high scientific and technological potential, etc. In this way, large companies have entered a new stage of 
multinationalization, namely the global redistribution of factors of production, and globalization has overcome the traditional paradigm of combining and using classical factors of production. Today, the world's largest corporations seek to gain advantages in production, marketing and research by combining factors of production on a global scale, due to the intensification of the economic globalization.

In view of the aspects highlighted above, and not only, we assert the following:

- firstly, the economic globalization is both a result of the intensification of the activity of the multinational companies and a cause of their growing assertions in the international environment;

- secondly, the recent data on the activity of the multinational companies confirm the trend to concentrate the business in the sectors with the greatest comparative advantages and towards markets with high demand potential, amplified by a high degree of openness and liberalization;

- thirdly, in the global economy, the size of the company determines its expansion across national borders, while creating an operational and financial synergy designed to reduce its vulnerabilities, to increase its ability to withstand various economic shocks more easily, and to exercise power over certain markets.

\section{Glocalization - An Objective Necessity that Influences the Performance of the Management of the Multinational Companies}

In recent decades, the experience gained by the multinational companies demonstrates that the greatest benefits have been obtained by those who have managed to quickly integrate the latest achievements of science and technology, while exercising a management adapted to the cultural specifics of the local markets. At the same time with the globalization of business, trade, information, etc., a process of localization, of fixation in space, was set in motion.

Consisting of the combination of the concepts of globalization and localization, in essence, the term glocalization represents the ability to think globally and act locally. Although at first glance it may seem like a relatively recent linguistic product, in fact the term glocalization appeared as early as 1980, in the business magazine "Harvard Business Review", and was brought back into discussion in 1992 by the British sociologist Roland Robertson, in his work "Globalization" and, later, in 1995, in another work entitled "Global Modernities", in the chapter "Globalization: Time-Space and Homogenity-Heterogenity". Robertson states that glocalization is "a compression of the world and an intensification of the consciousness of the world as a whole", as a process that simultaneously includes trends of universalization and individualization. In other words, glocalization involves taking a trend, idea, process, global product and adapting it to the local specifics.

In Roland Robertson's opinion, the global is not outside the local, but exists inside it, and globalization implies the particularization of the universalism and the universalization of the particularism. The global intertwines the local, and the globalization is achieved in real forms, which are local. In turn, the local is never "pure", or outside the global.

Unlike Robertson's approach to globality, contemporary trends suggest that globality is seen in terms of economic integration. The glocalization provided the means to emphasize Robertson's insistence that globalization implies both homogeneity and heterogeneity. In this sense, the McDonaldization, the theses of the cultural imperialism, or other similar arguments in favor of the cultural homogenization do not include an important aspect of global processes. Thus, as a result of the 
developing research, published in a variety of subjects and fields, the glocalization thesis has been extended to provide a more general approach to globalization as such (Khondker, 2005).

In Ritzer's interpretation, glocalization and the related notion of cultural heterogeneity are explicitly recognized as a viable theoretical alternative (Ritzer, 2003).

Because the international management can be practiced anywhere, the management process transcends national boundaries. Under these conditions, the international management is invariably much more complex, compared to running a business only within the national space.

Initially, most research in the field of management, starting from the premise of the universality of management, sought the "best solution" to manage that could be applied in any company, regardless of the national space and the cultural specifics. Subsequently, under the influence of the systemic approach, but especially of the contextual approach, theorists and even practitioners in the field of management came to the conclusion that management is practiced differently and that it has different results in countries with different cultures.

The contextual approach to management and the transfer of managerial know-how have a determining influence on the development of the international management research. According to this approach, the management system must be compatible with the particularities of the people and with the specifics of the environment in which it operates.

Professor Ovidiu Nicolescu advocates the need to conduct, at international level, a wide transfer of managerial know-how, respectively of dynamic, complex knowledge and experiences, which managers from certain cultures must take and adapt to the actual conditions under which they work (Nicolescu, 2001).
In its turn, the transfer of managerial know-how highlights a number of similarities and differences between the different national/local management models/practices, as well as the values, attitudes and experiences that can be transferred and used by other models. Within this transfer, as a result of the process of economic glocalization, two types of barriers can appear, namely:

- interpersonal (generated by language, ambiguities in perception, various asynchronizations, etc.);

-intersystemic (in the sense of the existence of codified schemes, of suspicions, of local pride, of specific organizational and individual attitudes, values and behaviors, etc.).

In current international practice, managerial know-how transfer is designed and operationalized in a variety of forms, not only in terms of content, but also methodologically. This diversity of methodological-applicative approaches most often reflects the differences in the degree of knowledge and understanding of the international cultural-managerial phenomenology and mastery of methods and techniques applicable to complex organizational changes. These inequalities influence differently the degree of rationality of the international transfer of know-how and, at the same time, the quality of the performances obtained by the respective companies.

In the context of glocalization, it is required to conduct a comparative analysis of the types of management (European, Japanese and American), as well as of their specificities, of the actual ways in which the transfer of the managerial know-how is carried out.

The influences on the activity and the behavior of the individuals, implicitly on the management, come from several levels, respectively societal, cultural, attitudinal and even at group or individual level (Burdus, 2012). The national variables 
(the economic system, the legal system, the political system, the education, the religion, the language) create the context for the development and perpetuation of the cultural variables (the norms, the values, the beliefs), which in turn are the foundation of the attitudes towards work, time, tasks, etc.

All these attitudes influence the relationships between the individuals, the staff motivation, the demands on work, the productivity and the work ethic. We consider that the differences manifested between these variables (at national, cultural, attitudinal and behavioral level) determine the differences in the management processes of the economic organizations. To what extent the management of the multinational companies is influenced by these variables and how the managers can anticipate the effects of the influence of the national culture on the managerial practices of the cultures in which they operate are challenges of the research in the international comparative management.

In order to increase their competitiveness and market value, the companies must also develop their international activities, the ability to act outside the national borders. The involvement of the managers in the international business can be done in several situations (such as: manager of a subsidiary of a multinational company; coordinator of activities that take place in other countries, in other cultures; negotiator with the suppliers or beneficiaries from other countries). The manager, involved in international business, must adapt to a dynamic, complex, difficult and different external environment from one country to another. The additional difficulties, specific to this environment, come from the differences in tradition, work ethic, in general from the differences in culture.

In international affairs, the manager fulfills the same roles, performs the same management functions as in a national company, especially if the environment in which he operates is multinational, multicultural or transcultural. A multicultural environment can be encountered by managers either in a multinational company or in a national company, in which groups of people from different cultures work and interact during the work process. The transnational environment is specific to companies operating in several countries. The branch manager of a multinational company, or transnational company, works in an operational environment with a specific culture, with its own regulations, having a staff with certain qualities, and so on. The roles or functions performed by him are also influenced by the specifics of the national environment in which the branch conducts its activity, as well as by the characteristics of the international environment. All these variables at the microeconomic, macroeconomic and mondoeconomic level influence the way the management functions are exercised (estimating, organizing, coordinating, training and controlling).

If initially, most research in the field of management, started from the premise of the universality of management, it sought the "best solution" to manage that could be applied in any company, regardless of the national space and cultural specifics, later on, under the influence of the systemic approach, but especially of the contextual approach, the theorists and even practitioners in the field of management have concluded that management is practiced differently and has different results in countries with different cultures.

As a result of glocalization, the companies need to adapt their products and experiences worldwide to suit the local specificities. Basically, the companies must have good knowledge and appreciation of the local markets and the requirements of each group of consumers/customers, in order to be fully successful. Many companies need to expand into markets 
beyond their own borders to achieve sustainable business and increase their profits. In order to be successful, the customer needs, the cultural differences and the business etiquette must be taken into account.

\section{Conclusions}

In order to exercise an efficient management within the multinational companies, we consider that, at the level of the local markets in which the company operates, it is imperative to identify and apply those good management practices that, filtered and adapted to the specifics of the organizational culture and the mentality of the employees, will contribute decisively to obtaining the competitive advantage. The permanently changing market conditions have become a constant feature of the global economic environment, forcing the multinational companies to practice creative, adaptive and efficient management, to constantly use the scientific tools of knowledge management, to focus not only on their own needs and expectations, but also to seek to meet, to a better extend, the requirements related to the specifics of the local markets in which they operate. These arguments lead us to argue that one of the viable solutions to the issues of the economic globalization, in the current economic and social context is the glocalization. It manages, to a much greater extent, to achieve an effective mediation between the global system and the local communities, keeping the stability of the global community and the win-win relationship between the actors involved. At the same time, the local practices and beliefs must be correctly identified and also complied with by the multinational companies.

\section{REFERENCES}

Angelescu, C. et al (2000). Economie. $5^{\text {th }}$ Edition, Bucharest: Economic Publishing House. House.

Burduș, E. (2012). Tratat de management. $2^{\text {nd }}$ Edition, Bucharest: Economic Publishing

Constantinescu-Băeșu, C. (1998). Globalizarea şi managementul. Available at: http://www.oeconomica.uab.ro/upload/lucrari/820063/12.pdf.

Gilpin, R. (2004). Economia mondială în secolul XXI. Provocarea capitalismului global. Iași: Polirom Publishing House.

Khondker, H.H. (2005). Globalization to glocalization: a conceptual exploration. Intellectual Discourse, Vol. 13, Issue 2, 181-199.

Negrea, A.P. (2012). Globalizarea și problema identitară. Economie teoretică și aplicată, Vol. XIX, Nr. 9(574), 69-70.

Nicolescu, O. (2001). Management comparat. Uniunea Europeană, Japonia și SUA. Bucharest: Economic Publishing House.

Popa-Paliu, L. (2009). Globalizarea economiei și internaționalizarea afacerilor. Analele Universității “Constantin Brâncuși” din Târgu-Jiu, Economy series, Nr. 3, p. 212.

Postelnicu, Gh., \& Postelnicu, C. (2000). Globalizarea economiei. Bucharest: Economic Publishing House. 
Pricop, M., \& Tanțău, A. (2001). Globalizarea și strategia firmei. Bucharest: Eficient Publishing House.

Ritzer, G. (2003). Rethinking globalization: glocalization /globalization and something/ nothing. Sociological Theory, Vol. 21, Issue 3, 193-209.

Vermen, R. (1966). International Investment and International Trade in the Product Cycle. Quarterly Journal of Economics, May, 190-207.

Wilson, E. (2012). Globality, in Ritzer, G. (ed.) The Wiley-Blackwell Encyclopedia of Globalization, $1^{\text {st }}$ Edition, Oxford: Wiley-Blackwell. 